\title{
The ability to recognize oneself from a video recording of one's movements without seeing one's body
}

\author{
T. BEARDSWORTH and T. BUCKNER \\ Trinity College, Oxford OXI $3 B \mathrm{BH}$, England
}

\begin{abstract}
Certain individuals are very much better than others at recognizing themselves from a recorded point-light display of their movements without being able to see their bodies. They are better at recognizing themselves in this way (although they have never seen themselves walking from an external point of view before) than they are at recognizing their friends, whom they see walking every day, and better than their friends are at recognizing them. This suggests some sort of kinesthetic-visual cross-modal transfer.
\end{abstract}

Wolff (1932), in his experiments on self-perception, claimed that whereas subjects frequently failed to recognize photographs of things they saw every day, such as their own hands and handwriting, they invariably recognized something they had never seen before, namely, a film of themselves walking, with face blocked out on the film and with bodily appearance disguised by loose clothing. He filmed eight subjects, five of whom knew each other before. They were $100 \%$ accurate at identifying themselves, but only $29.5 \%$ accurate (on average) at identifying each other.

Johansson (1973) has demonstrated in his experiments on motion perception that our visual system spontaneously abstracts relational invariances in the optical flow and constructs from them percepts of rigid objects moving in three-dimensional space. Applying this to the perception of human walking movements, he attached $1012-\mathrm{V}$ flashlight bulbs to the main joints of a man (see Figure 1) and filmed him walking in darkness. Within $.1 \mathrm{sec}$, or two motion picture frames, observers recognized the moving points of light as somebody walking, although when the lights were stationary they meant nothing.

In June 1976, Beardsworth (Note 1), in a pilot experiment, applied Johansson's (1973) technique for presenting human movement to Wolff's (1932) experimental approach. Six subjects, all known to each other, were asked to walk, one at a time, three times to and fro in front of a video camera, each wearing $1012-\mathrm{V}$ flashlight bulbs attached to their main joints. The 18 episodes were then shown in random order to the subjects. The results were less dramatic than Wolff's, but still striking: mean score for self-recognition, $66 \%$; for recognition of each other, $25 \%$.

The authors wish to thank P. Armitage of the Department of Biomathematics, Oxford University, for the statistical advice, and Michael Argyle for the use of the social psychology laboratory.
However, since the number of guesses in favor of self vs. others had not been controlled, it proved impossible to calculate the expectation of the two success rates. To take an extreme case, if somebody put down his name for all 18 episodes, he would then score $100 \%$ for selfrecognition and $0 \%$ for other-recognition, but the figures would be meaningless. In fact, nobody used his own name more than five times, but this was enough to make analysis of variance problematic. It would be interesting to know how Wolff (1932) coped with this problem, if at all.

Cutting and Kozlowski (1977) performed a similar experiment, but with different results, mean scores for self-recognition being $43 \%$, for other-recognition, $36 \%$. They concluded that self-recognition was not significantly better than recognition of others, "a result that fails to replicate Wolff." Statistically, their experiment was an improvement on Beardsworth's (Note 1) as regards sampling: Each of their six subjects walked to and fro 10 times, making a total of 60 episodes. But it is clear that they too failed to control the number of guesses in favor of different individuals; that is, their subjects may have guessed themselves more or less often than the average other person. Hence, the expectation of Cutting and Kozlowski's two success rates, $43 \%$ and $36 \%$, is not the same (on the null hypothesis that self-recognition is as easy as recognition of others), so the significance of the difference cannot be calculated (at least not without knowing the number of guesses by Subject A in favor of Subject B when the real walker was $\mathrm{C}$ ).

To overcome this problem, we decided to repeat the pilot experiment of Beardsworth (Note 1), but this time (1) like Cutting and Kozlowski (1977), using a total of $6 \times 10=60$ episodes, and (2) unlike Cutting and Kozlowski, constraining the number of each subject's guesses about himself to be 10 (and, consequently, the number of his guesses about others to be 50 ). 


\section{METHOD}

Each subject was dressed in a suit of overalls with $1012-\mathrm{V}$ flashlight bulbs attached to his main joints (to ankles, knees, elbows, and wrists, and to the hip and shoulder nearest the camera; see Figure 1). The bulbs were connected in series and attached by a long lead to a transformer. The room was sufficiently lit to facilitate walking, and each subject was videotaped as he walked past in front of the videocamera. When the tape was played back, contrast and brightness were adjusted to eliminate all visual information except the moving points of light.

Five students and one young teacher from Shimer College, Mount Carroll, Illinois, were selected as subjects, two females and four males, each of normal gait. All had known each other for 3-4 years before coming to Oxford for a semester, during which they saw each other daily. Subjects were briefed individually and performed the task while their friends waited in another room. Each was asked to sit in a chair until given the instruction "one brick" or "two bricks," when he was to get up, walk across the room, pick up one of two weights and place it on a stool, walk backward back to his chair, and sit down again. (The backward walking was necessitated by the trailing electric lead to the transformer.) The point of the "task" was to distract the subject from the act of walking. He was told that the purpose of the experiment was to see if an observer viewing the tape could tell whether the subject had picked up the lighter or the heavier weight (an experiment actually carried out by Johansson). The subject was recorded standing up, walking five or six paces from right to left past the camera, walking backward from left to right the same distance, and sitting down again. (Performance of the "task" took place off camera.) The camera was fixed $8 \mathrm{~m}$ from the subject at the nearest point; a wide-angle lens was used. The procedure was first demonstrated by the experimenter, then carried out once by the subject to familiarize him, and then recorded 10 times for each subject.

Each trial consisted of two such episodes by the same subject, linked together, taking a total of about $20 \mathrm{sec}$ viewing time. The first five episodes of all subjects were linked in this way $(1-2,2-3,3-4,4-5,1-5)$ and transferred in random order

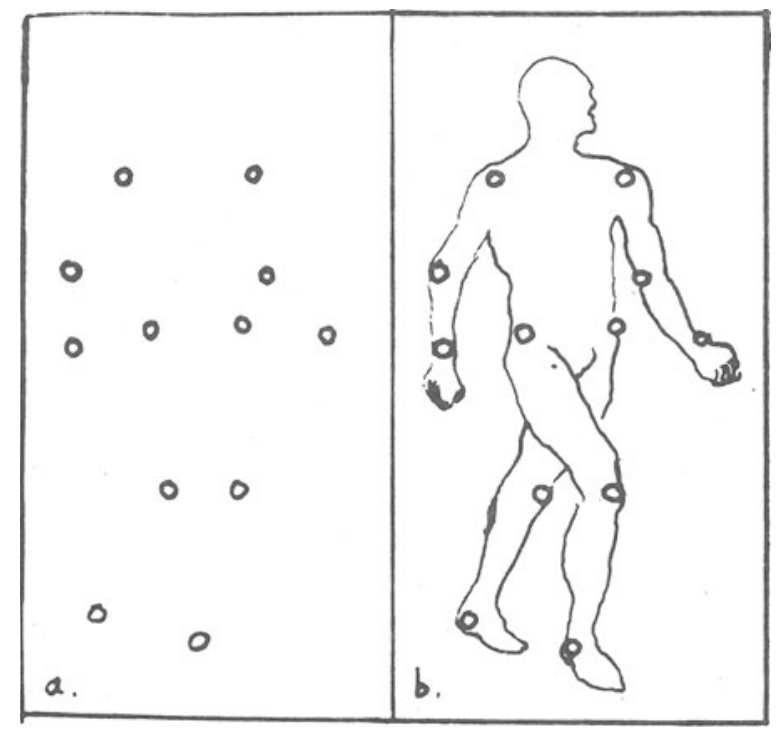

Figure 1. Small lights are attached to the main joints of a subject (b). When the lights are stationary, they mean nothing (a). But as soon as the subject begins to move, the lights are immediately recognizable as constituting a walking person.
Table 1

Who Recognized Whom?

\begin{tabular}{lrrrcrcc}
\hline & \multicolumn{7}{c}{ Walker } \\
\cline { 2 - 7 } Viewer & \multicolumn{1}{c}{1} & \multicolumn{1}{c}{2} & \multicolumn{1}{c}{3} & $4^{*}$ & $5^{*}$ & 6 & Mean \\
\hline 1 & 90.0 & 20 & 50 & 20.0 & 60.0 & 40.0 & 46.7 \\
2 & .0 & 80 & 0 & 20.0 & 40.0 & 20.0 & 26.7 \\
3 & 80.0 & 0 & 70 & 40.0 & 50.0 & 40.0 & 46.7 \\
$4^{*}$ & 80.0 & 30 & 40 & 60.0 & 20.0 & 40.0 & 45.0 \\
$5^{*}$ & 70.0 & 20 & 40 & 30.0 & 50.0 & .0 & 35.0 \\
6 & .0 & 30 & 40 & 20.0 & 10.0 & .0 & 16.7 \\
Mean & 53.3 & 30 & 40 & 31.7 & 38.3 & 23.3 & $36.1 \dagger$ \\
\hline
\end{tabular}

Note-Figures give percentage of correct identifications. Overall recognition of self $=58.3 \%$; overall recognition of others $=$ $31.6 \%$ *Female. tOverall mean.

onto a 30-trial tape, with $10 \mathrm{sec}$ separating each trial. The last five episodes were similarly linked and transferred in random order onto another 30-trial tape. Tape 1 was shown to the subjects 7 days after the recording session; Tape 2 was shown 2 days later. The purpose of dividing the viewing into two parts in this way was to enable us effectively to constrain the number of the subject's guesses about themselves to five on each occasion. At the first viewing session, Tape 1 was shown twice: The first time through, subjects were instructed to try to identify each person, given that each person was featured five times; the second time through, they were instructed to modify their previous answers so as to ensure that their own name occurred five times and five times only. At the second viewing session, Tape 2 was shown twice in the same way.

\section{RESULTS AND DISCUSSION}

Overall, correct responses occurred on $36.1 \%$ of all trials (130/360), a figure close to Cutting and Kozlowski's (1977) 38\%. The success rate clearly exceeds the chance expectation of 1/6: If all the responses had been unconstrained guesses with an expected success probability of $1 / 6$, our results would give $\chi^{2}(1)=98.0$, very highly significant. The design constraints affect this result only very slightly: If all subjects had chosen each other subject precisely 10 times, we should have had $\chi^{2}(1)=94.7$.

The figure for self-recognition, however, was much higher than Cutting and Kozlowski's (1977), 58.33\% (compared with 43\%); that for the recognition of others was somewhat lower, $31.67 \%$ (compared with 36\%). Comparing the proportion of correct guesses about themselves $(35 / 60$, or .5833$)$ with the proportion of walks by others mistaken for their own $(25 / 300$, or $.0833)$, the difference is highly significant $\left[\chi^{2}(1)=\right.$ $90.0]$. As for recognition of others, since 275 walks by others were attributed to others, one would expect (if all guesses were random) that a proportion of $1 / 5$ would be correct; in fact, $95 / 275=.3455$ were correct; the excess is again highly significant $\left[\chi^{2}(1)=36.4\right]$.

The overall success rates, .5833 for self-recognition and .3167 for recognition of others, would differ significantly from each other if the responses were unconstrained and if the subjects were completely homogeneous in their success rates. As noted earlier, the 
design constraints are unlikely to affect the significance at all materially, but the homogeneity of subjects' success rates is a more important point. Our later discussion of individual results shows that at least two of the subjects (Subjects 1 and 2) clearly exhibit such a difference (see Table 1). This is in contrast to Cutting and Kozlowski's (1977) conclusion and in support of Wolff's (1932).

Why is there a discrepancy from Cutting and Kozlowski's (1977) findings? There are several possible reasons: First, Cutting and Kozlowski did not constrain their subjects' number of guesses about themselves to 10 , which may have allowed some of the subjects to be unduly self-effacing, guessing themselves less often than the average other person. Second, each trial in the Cutting and Kozlowski study lasted less than $6 \mathrm{sec}$ and consisted simply of the subject's walking from right to left and back once, whereas in the present study each trial lasted about $20 \mathrm{sec}$ and consisted of the subject's standing up, walking from right to left, walking back backward, sitting down, and then repeating the procedure. Third, our subjects, unlike those of Cutting and Kozlowski were given a "task" to perform to distract them from self-consciousness of movement while walking.

But how can a person recognize himself, whom he has never seen walking from an external point of view before, better than he does his friends, whom he sees walking every day, and better than his friends do him? The phenomenon suggests some sort of postural empathy or identification (Hebb, 1960); we may postulate a sort of kinesthetic-visual cross-modal transfer that applies not just to the movements of certain visible parts of one's body, but to one's body as a synergic whole. A similar mechanism is suggested by Hebb to account for such phenomena as involuntary imitation and the occurrence of autoscopic hallucinations under conditions of sensory monotony. Our subjects were asked whether they made their identifications immediately ("I just knew") or by inference ("That must be X because of his bouncy stride"). Interestingly, Subjects 1 , 2 , and 3, who scored highest on self-recognition and showed no improvement with practice (they alone scored as high on Tape 1 as on Tape 2), said they recognized themselves immediately; the rest (and Subjects 1,2 , and 3 on other-recognition) said they used inference, and they tended to show improvement with practice.

\section{Individual Differences}

As noted earlier, the success rates (for self and for others) may vary significantly between individuals, so that their differences may not be homogeneous. Accordingly, the difference in proportions for each subject was calculated, to see whether these differences appeared to be homogeneous, and, if so, to get a weighted mean difference. The weights are reciprocals of variances, based on the assumption that the two propor- tions are statistically independent (i.e., ignoring the minor design constraints). The sums are shown in Table 2. Homogeneity of the differences can be tested by $\chi^{2}=\Sigma w^{2}-(\Sigma w d)^{2} / w$. This gives $\chi^{2}(5)=25.7$, quite highly significant. In other words, our subjects vary in the degree of difference between their ability to recognize themselves and their ability to recognize others. In fact, taking the standard error of $d_{i}$ to be $1 / \sqrt{w_{i}}$, Subjects 1 and 2 are clearly better at recognizing themselves than others, and Subject 3 is marginally so.

Marked individual differences were also a feature of Beardsworth's (Note 1) pilot experiment and of Cutting and Kozlowski's (1977) experiment. Why should some people be so much better than others at recognizing themselves in this way? Subject 1 was most easily recognized by three of his friends (Subjects 3, 4, and 5), as well as by himself, probably because of his relatively rapid gait, so his ability in this respect is probably less remarkable. But Subject 2 was hardest (on average) for his friends to recognize (mean $=20 \%$ ), yet he recognized himself 8 times out of 10 , while failing to score above chance at recognizing others. Conversely, Subject 6 failed to recognize himself at all, but was marginally better at recognizing others.

According to Witkin, the "field-independent" person "experiences his body as a separate entity, segregated from the field" (1965, p. 33); such people "experience their bodies as having definite limits or boundaries and the parts within as discrete yet inter-related and formed into a definite structure" (1962, p. 116), whereas the "field-dependent" person experiences his body "as a vague mass, not clearly segregated from its surroundings" (1962, p. 133) (cf. Michotte, 1963, pp. 204-205: "The body appears as a somewhat shapeless mass or volume. There is very little by way of internal organization or connection between the parts ... the special peculiarities of the kinaesthetic body [are] its 'fluidity,' the lack of internal differentiation and organization, the absence of precise boundaries"). On the other hand, field-dependent people are "particularly attentive to others, especially to facial characteristics and expressions" (Witkin, 1962, p. 148). That their ability to recognize or recall faces is superior to that of field-independent people was demonstrated in an experiment by Crutchfield, Woodworth, and Albrecht (Note 2). With this in mind, we gave our subjects one of Witkin's three criterion tests for field independence, the Embedded Figures Test.

Table 2

\begin{tabular}{|c|c|c|c|c|}
\hline Subject, i & $\begin{array}{l}P_{i_{1}} \\
\text { Self }\end{array}$ & $\begin{array}{c}\mathbf{P}_{\mathbf{i}_{2}} \\
\text { Others }\end{array}$ & $\mathbf{P}_{\mathbf{i}_{1}} \stackrel{\mathrm{d}_{\mathbf{i}}}{-} \mathbf{P}_{\mathbf{i}_{2}}$ & $\begin{array}{c}w_{i}=1 / v a r \\
\left(P_{i_{1}}-P_{i_{2}}\right)\end{array}$ \\
\hline 1 & .90 & .38 & .52 & 73 \\
\hline 2 & .80 & .16 & .64 & 54 \\
\hline 3 & .70 & .42 & .28 & 39 \\
\hline 4 & .60 & .42 & .18 & 35 \\
\hline 5 & .50 & .32 & .18 & 34 \\
\hline 6 & .00 & .20 & -.20 & 60 \\
\hline Total & & & & 295 \\
\hline
\end{tabular}


Interestingly, and in conformity with our expectations, Subject 2 attained by far the highest score of the group, $75 \%$ (mean $=43.3 \%)$, whereas Subject 6 scored only $35 \%$. Also interesting is the fact that 8 of 10 times Subject 6 mistook Subject 1 for himself. Subject 1 was his teacher, and insofar as field-dependent people "require greater guidance and support" and are "more dependent on authority," this gives grounds for speculating about the possibility of unconscious self-identification with the other.

We conclude that, while people tend to be better at recognizing themselves in this way than recognizing their friends, surprising though this is, it is less interesting than the marked individual differences between their success rates, which calls for further investigation.

\section{REFERENCE NOTES}

1. Beardsworth, T. Gait recognition of self vs. others. Unpublished study, 1976.

2. Crutchfield, R. S., Woodworth, D. G., \& Albrecht, R. E. Perceptual performance and the effective person (Report No.
WADC-TN-58-60, ASTIA Doc. No. AD 151 039). San Antonio, Tex: Personnel Laboratory, Lackland Air Force Base, 1958.

\section{REFERENCES}

CutTing, J. E., \& Kozlowski, L. T. Recognizing friends by their walk: Gait perception without familiarity cues. Bulletin of the Psychonomic Society, 1977, 9, 353-356.

Hesв, D. O. The American Revolution. American Psychologist, $1960,15,735-745$.

Johansson, G. Visual perception of biological motion and a model for its analysis. Perception \& Psychophysics, 1973, 14, 201-211.

Michotтe, A. The perception of causality. London: Methuen, 1963.

Witkin, H. A. Development of the body concept. In S. Wapner \& H. Werner (Eds.), The body percept. New York: Random House, 1965.

Witkin, H. A., Dyk, R. B., Faterson, H. F., Goodenough, D. R., \& KARp, S. A. Psychological differentiation. New York: Wiley, 1962.

WoLFF, W. Selbstberteilung und Freundberteilung in Wissentlichen und Unwissentlichen Versuch. Psychologische Forschung, 1932, 16, 251-328.

(Received for publication May 25, 1981.) 